\title{
FACTORS CONTROLLING
}

\section{GAS TURBINE COMBUSTION \\ PERFORMANCE AT HIGH}

PRESSURE.

by

A.H. Lefebvre

(Paper prepared for presentation at the 78th meeting of the G.T.C.C. Combustion Sub-Committee, February 1965).

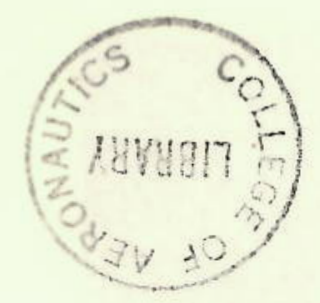




\section{INTRODUCIION}

In the past most of the research work carried out in gas turbine combustion was mainly concerned with performance problems arising at high altitudes. These were primarily problems of trying to achieve high combustion efficiency, adequate stability and good relighting performance. This research necessitated the use of expensive test facilities to provide large quantities of air at sub atmospheric pressure. For this reason much effort was expended in trying to find methods of simulating low combustion pressures, and in the development of correlating parameters which would allow low pressure performance to be predicted from experimental data obtained at more convenient levels of pressure.

In recent years, however, there has been a marked trend towards engines of higher compression ratio. This is illustrated in figure 1 which was reproduced from a paper by Pearson ${ }^{1}$. This trend has not produced any new problems, with the possible exception of exhaust smoke, but it has aggravated many problems which previously caused no great concern, and it has exposed many deficiencies in our knowledge of certain basic processes, particularly those affecting combustion and heat transfer at high pressure. One object of this paper is to examine the influence of pressure on various aspects of combustion performance. Another object is to derive formulae from which the influence of increasing pressure on various performance criteria can be estimated.

One important effect arising at high pressures is an increased dependence of all aspects of coibustion performance on fuel spray characteristics. Because of their importance and because so far they appear to have received comparatively little attention, much of this paper is devoted to the effect of pressure on various spray properties such as penetration, droplet size and cone angle. 


\section{COMBUSTION PERFORMANCE}

Combustion performance is usually considered to include stability, ignition characteristics and combustion, efficiency. However; sínce it is known that the problems of stability and ignition diminish with increasing pressure, we need concern ourselves only with the influence of pressure on combustion efficiency. This is illustrated in figure 2 which shows four regimes of piessure. In the first regime, corresponding to pressures of a few p.s.i.a., combustion is impossible due to the effects of poor atomisation and heat losses. In the second regime, which extends approximately from 2 to 20 or 30 p.s.i.a., depending on the size of the chamber, the level of combustion efficiency is determined almost entirely by chemical reaction rates, with atomisation playing only a secondary role. The third regime corresponds to nomal chamber operation and provides a range of pressures in which the combustion efficiency is close to 100 percent.

With increasing pressure the level of combustion efficiency becomes less dependent on reaction rates and more dependent on the ability of the combustion zone to evaporate the fuel and achieve the necessary mixing between fuel vapour, air and combustion products. The possibility exists, therefore, that at extremely high pressures the combustion efficiency may start to fall off due to limitations imposed by evaporation and/or mixing rates. This is indicated as the fourth regime in figure 2.

In a combustion chamber the fuel spray contains droplets of various sizes which are separated from each other by a multiplicity of distances. For the case of a single fuel droplet the evaporation is achieved by heat transferred from the surrounding flame whose burning rate is determined by the rate of evaporation of fuel from the drop. In a spray, however, the large number of droplets burning in close proximity can produce such high vapour concentrations that the rate of burning is 
not limited by the evaporation rate but by the process of mixing between the fuel vapour and the oxidant. If the rates of mixing and evaporation were extremely high, the combustion process would simulate a homogeneous chemical reaction. In practice, however, the rate of evaporation is limited by the problerus involved in trying to produce fuel which is well atomised and, at the same time, well distributed throughout the combustion zone. Moreover, the rate of mixing is controlled by the available pressure loss and by the need to maintain combustion over a wide range of fuel/air ratios.

In the following sections an attempt will be made to examine the influence of pressure on evaporation rates, with a view to determining the relative importance of evaporation and mixing processes at high pressure.

\section{Fuel evaporation and droplet lifetime}

Following Godsave ${ }^{2}$ we have, for a single droplet

$$
\begin{aligned}
& \frac{d m}{f_{f} d t}=\frac{d}{d t} \frac{\pi d^{3}}{6}=\frac{\pi d^{2}}{2} \frac{d d}{d t}=-\frac{\pi}{4} \lambda d . \\
& \text { from which } \frac{d m}{d t}=-\frac{\pi}{4} e_{f} \lambda d \\
& \text { and } t=\frac{d_{0}^{2}}{\lambda}
\end{aligned}
$$

$$
\text { where } \begin{aligned}
m & =\text { mass of drop } \\
d & =\text { diameter of drop } \\
d_{0} & =\text { initial diameter of drop } \\
\varphi_{+} & =\text {fußl density } \\
\lambda & =\text { evaporation constant } \\
t & =\text { drop lifetime }
\end{aligned}
$$

Hall and Diederichsen ${ }^{3}$ found that for any given drop size the drop lifetime was inversely proportional to the fourth root of the gas pressure.

$$
\text { i.e. } \quad t \propto \frac{1}{p^{0.25}}
$$

Incorporating this result into eqn. (1) gives

$$
t \propto \frac{d^{2}}{p^{0.25}}
$$

For any given fuel varies only slightly with pressure. Hence we can write

$$
t \propto \frac{d^{2}}{p^{0} \cdot 25}
$$


Equation (3) applies strictly only to stationary drcps. When the droplet is in motion relative to the surrounding gas the rate of evaporation is increased. The following equation, due to Frossling ${ }^{4}$ has been found to correlate successfully a wide range of data on the evaporation of small drops in motion.

$$
\begin{aligned}
\frac{M_{S} d}{D e \log (1+3)} & =2\left[1+0.276(\mathrm{Re})^{0.5}(\mathrm{Sc}) 0.33\right] \\
\text { where } M_{S} & =\text { rate of droplet evaporation/unit surface area } \\
d & =\text { drop diameter } \\
D & =\text { diffusion coefficient } \\
P & =\text { gas density } \\
B & =\text { evaporation constant } \\
R e & =\text { Reynolds No. } \\
\text { Sc } & =\text { Schmidt No. }
\end{aligned}
$$

In the above equation $B$ decreases slightly with pressure but the actual variation is small and for most practical purposes it is satisfactory to regard $B$ as a constant. Moreover, if temperature terms are neglected, the product $\rho D$ is also constant, and eqn. (4) simplifies to

$$
\frac{d m}{d t} \propto u^{0.5} \quad p^{0.5} \quad d^{1.5}
$$

Now

$$
\frac{d m}{d t}=\frac{d m}{d d} \cdot \frac{d d}{d t}
$$

and

$$
\frac{d m}{d d}=\frac{\rho_{f} \pi d^{2}}{2}
$$

Dividing $(5)$ by $(6)$ and assuming $\rho_{f}=$ constant, yields

$$
\frac{d d}{d t} \propto \frac{u^{0.5} p^{0.5}}{d^{0.5}}
$$

which may be integrated to give

$$
t \propto \frac{d_{0}^{1.5}}{U^{0.5} p^{0.5}}
$$

$$
\text { where } \begin{aligned}
t & =\text { droplet lifetime } \\
d_{0} & =\text { initial droplet diameter } \\
U & =\text { droplet velocity relative to ge.s } \\
p & =\text { gas pressure }
\end{aligned}
$$


From equations (3) and (7) we have the following expressions for froplet lifetime.

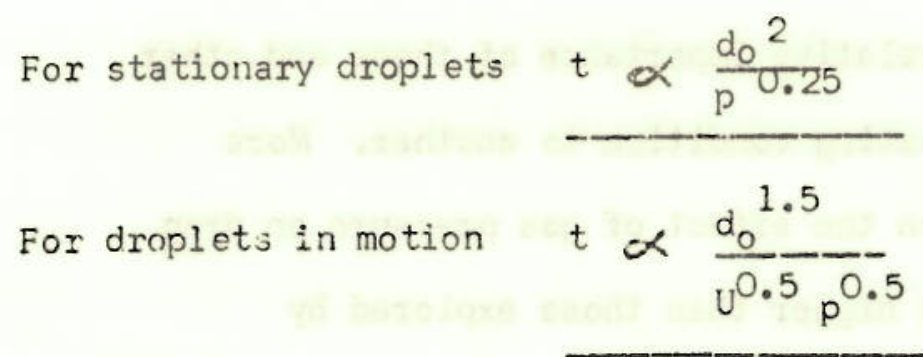

It might be expected that eqn. (7) should be the most appropriate for gas turbine application. Unfortunately, however, it is strictly true only for droplet Reynolds Numbers which are significantly higher than those normally encountered in gas turbine combustion. For this reason droplet lifetimes have been evaluated using both equations ( 3 ) and (7).

Equation (7) shows how the lifetime of individual drops, and hence the rate of combustion of the spray as a whole, is largely determined by the size of the drop. It is, therefore, important to ascertain how dropiet size is affected by atomiser flow characteristics and by variations in combustion pressure.

\section{Drop size}

Miessa ${ }^{5}$ found at sub atmuspheric pressures that drop size decreased with pressure according to the relationship $d \propto p^{-0.2}$. De Corso ${ }^{6}$, using swirl type atomisers, al so found that at low pressures drop size decreased with increasing prəssure. However, in the tests carried out at gas pressures and fuel pressures similar to those enco'untered in engines, very little variation in drop size with pressure was observed. The mechanism of atomisation at high pressures is not clear. When the fuel pressure drop is high atomisation takes place close to nozzle orifice. The spray intensity is high and, under the turbulent conditions prevailing in combustion chambers, the collision rate between drops must also be expected to be high. Collisions resulting in coagulation can cause an 
appreciable increase in average drop size. However, very energetic collisions can give rise to secondary atomisation and hence to a reduction in drop size. The relative importance of these and other effects may vary from one operating condition to another. More experimental data are needed on the effect of gas pressure on drop size particularly at pressures higher than those explored by De Corso, i.e. > 120 p.s.i.a.

De Corso found an appreciable effect of fuel pressure on droplet size which is consistent with the earlier results obtained by N.G.T.E., Lucas and Shell.

The N.G.T.E. formula for kerosine is

$$
\begin{aligned}
& d_{m}=300 \cdot \frac{Q^{0.25}}{p^{0.4}} \\
& \text { where } d_{m}=\text { Sauter mean diameter } \\
& \text { of drop, microns } \\
& Q=\text { fuel flow, gallons/hour } \\
& \mathrm{P} \text { = fuel pressure drop, } p_{\bullet} \text { s.i. } \\
& \text { Now } Q=F P^{0.5}
\end{aligned}
$$

where $F$ is the atomiser flow number

Substitution of (9) in (8) gives

$$
d_{m}=300 \frac{F^{0.25} P^{0.125}}{P^{0.4}}
$$

$$
\text { or, } d_{m}=300 \quad \frac{F^{0.25}}{P^{0.275}}
$$

$$
\text { or } d_{m} \alpha\left(\frac{F}{P}\right)^{\frac{1}{4}}
$$

Equation (11) may be found useful as a ready means of comparing the mean droplet size at various conditions on the same engine or between two different engines.

From eqn. (9) we have, for any given engine, $Q \propto P$. Substituting this relationship into eqn. (8) gives

$$
\mathrm{dm} \propto \frac{Q^{0.25}}{Q^{0.8}} \propto \frac{1}{Q^{0.55}}
$$


Now the air pressure is roughly proportional to the engine mass flow which, for any given fuel/air ratio, is proportional to Q.

$$
\text { hence } d m \leadsto \frac{\text { constant }}{p^{0.55}}
$$

Equation (12) proviaes a useful relationship between mean droplet size and pressure although its application is necessarily restricted to one specific engine.

\section{Effect of pressure on evaporation rates}

\section{Case 1. Effect of operating pressure}

We have, from eqn. (3) $t \propto \frac{d_{0}^{1.5}}{U^{0.5} p^{0.5}}$

To any given engine

$$
\begin{array}{ll}
\text { and } & \mathrm{U} \propto \mathrm{p} 0.5 \\
\text {.l so } & \mathrm{P} \propto \mathrm{Q}^{2} \propto \mathrm{p}^{2}
\end{array}
$$$$
d m \propto p^{-0.55}
$$

(eqn. 12)

Substituting (14) into (13) and (12) and (13) into (4) yields

$$
t \propto p^{-1.82}
$$

Now the time available for evaporation is proportional to a characteristic dimension of the flanetube, such as the diameter or widtin, divided by the reference velocity

$$
\begin{aligned}
& \text { i.e. avaiiable evaporation time } \propto \frac{A \cdot D \cdot P_{2}}{M_{2} I_{2}} \\
& \text { where } M_{2}=\text { chamber inlet air mass flow } \\
& P_{2}=" \text { " "pressure } \\
& \mathrm{I}_{2}=" \text { " "temperature } \\
& A=\text { chamber reference area } \\
& D=" \text { " dimension }
\end{aligned}
$$

For a constant value of $\frac{\mathrm{M}_{2} \mathrm{~T}_{2}}{\mathrm{P}_{2}}-5$ and constant comblistor dimensions eqn. (16) becomes

$$
\begin{aligned}
& \text { available evapoiation time } \propto \mathrm{T}^{-0.5} \\
& \text { or, " " } \quad 2 \times p^{-0.142} \\
& \text { since } T \text { or } p^{0.284}
\end{aligned}
$$


If we now define an "evaporation performance number" $E$, as the ratio of time available for evaporation to the time required for evaporation, then for any given engine

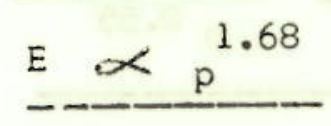

Had equation (3) which describes the lifetime of a stationary droplet been used,

$$
\begin{aligned}
& \text { then } t \propto p^{-1.35} \\
& \text { and } E \propto p^{1.2}
\end{aligned}
$$

Equation (16) shows that for any given engine the problem of fuel evaporation diminishes appreciably with increasing pressure. Since reaction rates also increase markedly with pressure, it follows that any observed deterioration in combustion efficiency with increase in pressure must be attributed to inadequate mixing.

\section{Case 2. Effect of design pressure ratio}

Consider two engines of the same size and same $\frac{M T \cdot 5}{\mathrm{P}}$ and featuring similar designs of combustion chamber, but one having a pressure ratio ' $R$ ' times the other. When both are operating at maximum pressure we have -

(1)
(2)

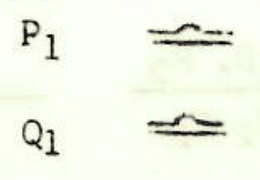

$$
\begin{aligned}
& \mathrm{P}_{2} \\
& \text { Now } \quad t \propto \frac{\mathrm{d}^{1.5}}{\mathrm{u} \cdot 5} \\
& \text { where } \quad d \propto R^{0.25}, T^{-0.125} \\
& \mathrm{p} \propto \mathrm{R} \\
& u=f(P)=\text { constant } \\
& \text { hence } t \propto \frac{R^{0.375}}{R^{0.5}}
\end{aligned}
$$$$
\text { R. } T^{-0.5} Q_{2} \cdot \quad\left(\begin{array}{l}
\text { where } T=\text { ratio of } \\
\text { inlet air temperature }
\end{array}\right)
$$$$
\mathrm{F}^{0.25} \mathrm{~T}^{-0.125} \mathrm{~d}_{2}
$$ 


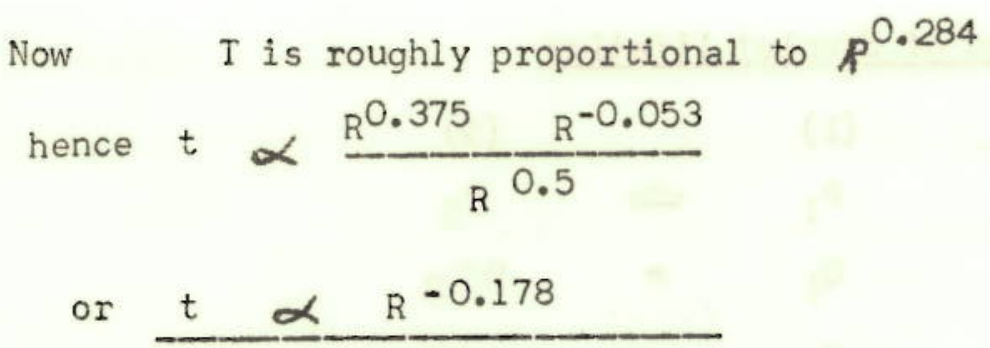

As in the previous case the available evaporation time is

$$
\begin{aligned}
& \text { proportional to } \mathrm{R}^{-0.142} \\
& \text { Hence } E=\frac{1}{\mathrm{R}^{0.142}} \div \frac{\frac{1}{\mathrm{R}^{0.178}}}{\text { or } E \propto \mathrm{R}^{-0.036}}
\end{aligned}
$$

Thus in engines of the same size but of different pressure ratio, the ratio of available evaporation time to required evaporation time is practically the same, and hence their evaporation performance is the same. However, if the droplet lifetime is calculated from equation (3)

then

$$
\text { and } \begin{array}{lll}
t & \propto & \propto \\
\hline
\end{array}
$$

Thus equation (19a) predicts an adverse affect of increasing design pressure ratio on evaporation performance.

\section{Case 3. The general case}

Let us consider now the general case of engines varying in size, pressure ratio and combustion chamber design. Let $M$ and $R$ denote respectively the ratios of mass flow and pressure of two engines both operating at their maximum pressure and at the same fuel/air ratio.

Also let $\mathrm{N}=$ ratio of number of fuel injectors

$$
\begin{aligned}
& \frac{\Delta p}{p}=\text { fractional pressure loss in chamber } \\
& \frac{\Delta p}{q}=\text { pressure loss factor of chamber }
\end{aligned}
$$


(a) Calculation of droplet lifetime

(1)

$\begin{array}{lll}P_{1} & \approx & P_{2} \\ Q_{1} & =M Q_{2} \\ F_{1} & =\quad M \cdot N^{-1} \cdot F_{2}\end{array}$

From eqn. (8) $d_{1}=M^{0.25} N^{-0.25} d_{2}$

In eqn. (7)

$t \propto \frac{d^{1.5}}{U^{0.5} p^{0.5}}$

We have

$$
\begin{aligned}
& d \propto M^{0.25} N^{-0.25} \\
& U=f(P)=\text { constant } \\
& p \propto R
\end{aligned}
$$

Substitution in (7) gives

$$
t \propto \frac{M^{0.375}}{N^{0.375}}-\frac{R^{0.5}}{20}
$$

(b) Calculation of available evaporation time

$$
\text { Available evaporation time } \propto \frac{D}{V}
$$

$$
\text { Now } V=\frac{M_{2}}{A} \frac{T_{2}}{P_{2}}
$$

But $\frac{M_{2} T_{2} 0.5}{A P_{2}} \propto\left(\frac{\Delta P}{P_{2}}\right)^{0.5}\left(\frac{\Delta p}{q}\right)^{-0.5}$

$$
\text { Hence } \quad v \propto\left(\frac{\Delta p}{P_{2}}\right)^{0.5} \quad\left(\frac{\Delta p}{q}\right)^{-0.5} \mathrm{~T}_{2}{ }^{0.5}
$$

Also from (22) A $\quad \alpha \frac{M_{2} T_{2}}{P_{2}}-\left(\frac{\Delta p}{P_{2}}\right)^{-0.5}\left(\frac{\Delta p}{q}\right)^{0.5}$

$$
\text { and } \left.\quad D \propto\left(\frac{\mathrm{M}_{2} \mathrm{~T}_{2}}{\mathrm{P}_{2}}\right)^{0.5}\right)^{0.5}\left(\frac{\Delta \mathrm{P}}{\mathrm{P}_{2}}\right)^{-0.25}\left(\frac{\Delta \mathrm{P}}{\mathrm{q}}\right)^{0.25}
$$

Substituting equations (23) and (24) into (21) gives

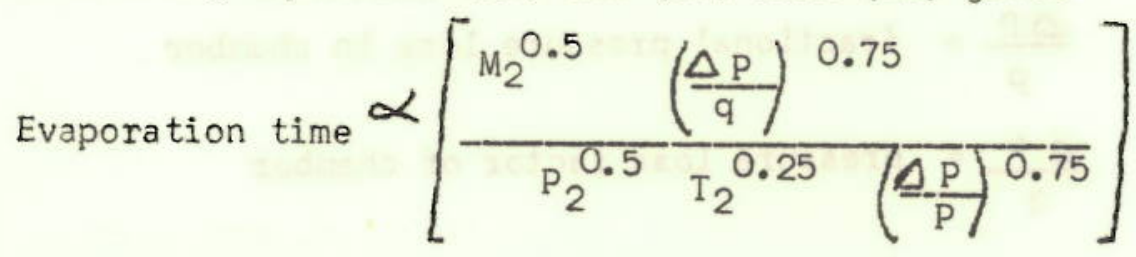

Substitution for $M_{2}=M, P_{2} \alpha R$, and $T_{2} \propto R^{0.284}$ yields

available evaporation time $\alpha \frac{M^{0.5}}{R^{0.572}} \frac{\left(\frac{\Delta p}{q}\right)^{0.75}}{\left(\frac{\Delta P}{P}\right) 0.75}$

Hence $E=\frac{\text { available evaporation time }}{\text { required evaporation time }}$ 


$$
\begin{aligned}
& \text { - } 11- \\
& E \alpha \frac{M^{0.125}}{R^{0.072}} \frac{N^{0.375}}{\left(\frac{\Delta p}{p}\right)^{0.75}}
\end{aligned}
$$

For the case of the stationary droplet

$$
\begin{aligned}
t & \propto M^{0.5} N^{-0.5} R^{-0.25} \\
\text { and } E & \propto \frac{N^{0.5}}{R^{0.32}} \frac{\left(\frac{\Delta P}{q}\right)^{0.75}}{\left(\frac{\Delta P}{P}\right)^{0.75}}
\end{aligned}
$$

Equation (25) applies when the droplet Reynolds No. is high, i.e. at high pressures, and tquation (27) is appropriate when the Reynolds No is low, i.e. at altitude. Both equations show that evaporation performance is improved by an increase in number of atomisers and combustor pressure loss factor, and is adversely affected by an increase in combustor pressure loss.

Equation (25) also suggests that evaporation performance is virtually unaffected by engine pressure ratio but is improved slightly by an increase in engine mass flow.

\section{EXHAUST SMOKE}

The problem of exhaust smoke has been discussed in some detail by Lefebvre and Durrant. ${ }^{7}$ As a result of tests carried out on the influence of fuel spray characteristics on smoke formation, they put forward the view that smoke is produced mainly in the fuel rich region in the centre of the flame-tube adjacent to the atomizer. It was concludied, therefore, that "any modification which reduces the concentration of fuel in this region effectively reduces smoke". In this context the spray characteristics of primary importance are the spray angle and the spray penetration. These are discussed below in turn. Spray angle

The effect of gas pressure on spray angle has been examined experimentally by De Corso. He found that spray angle remained sensibly 
constant up to a certain value of pressure, above which it was appreciably reduced by any further increase in pressure. According to Ducarme ${ }^{8}$ this contraction of the spray with increasing gas pressure is caused by a pressure difference between the gases outside and inside the spray which is proportional to the fuel injection pressure drop. For any given atomiser, as the gas pressure is increased the fuel pressure also increases and eventually a fuel pressure drop is reached when the angle of the spray begins to contract.

\section{Spray penetration}

The effect of pressure on the spray as a whole may be estimated by considering the factors governing the penetration of a single droplet.

An expression for the penetration of a droplet into a stagnant gas may be derived as follows:-

If $F$ is the aerodynamic drag force on the droplet, then

$$
\begin{aligned}
& F=C_{D} \cdot A_{C} \cdot \frac{\rho_{q} U^{2}}{2 g} \\
& \text { where } A_{d}=\text { cross sectional area of droplet } \\
& \rho_{\mathrm{g}}=\text { gas density } \\
& \mathrm{U}=\text { droplet velocity } \\
& C_{D}=\text { drag coefficient for evaporating } \\
& \text { spherical droplet. } \\
& \text { Now } F=-\frac{m}{g} \frac{d U}{d t} \\
& \text { where } m \text { is the mass of the droplet. } \\
& \text { Substitution for } F \text { in equations (28) and (29) gives } \\
& \frac{d U}{d t}=-C_{D} \cdot \frac{A d}{m} \cdot \frac{\rho g U^{2}}{2}
\end{aligned}
$$

The distance travelled by a droplet before being brought to rest is equal to the time of travel multiplied by the average velocity. According to Ingebo 11

$$
\begin{gathered}
C_{D}=27(R e)^{-0.84} \\
\text { Also, } A_{d}=\frac{\pi}{4} d^{2} y=m=\frac{\pi}{6} d^{3} \text { and } \eta \propto T^{0.66 .}
\end{gathered}
$$


Subotitution for $C_{D}, A_{d}, m$ and 7 in eqn. (30) gives

$$
\frac{d U}{d t}-\frac{p^{0.16} T^{0.34} U^{1.16}}{d^{1.84}}
$$

Now $\quad \frac{d U}{d t}=\frac{d U}{d S} \cdot \frac{d S}{d t}=\frac{d U}{d S} \cdot U$.

Hence $d S=\frac{U \cdot d U}{d V / d t}$

Substituting $\frac{d U}{d t}$ from eqn. (3!) into eqn. (32) and

integrating gives

Penetration distance $S \propto \frac{U^{0.84} d^{1.84}}{p^{0.16} T^{0.34}}$

It is of interest to compare equation (33) with the following expression for penetration distance obtained, according to Stewart, ${ }^{9}$ by Bayley ${ }^{10}$ using graphical methods.

$$
s \propto \frac{U^{0.9}}{p^{0.14}} \frac{d 1.8}{T^{0.055}}
$$

Substitution in eqn. (33) for $U \propto \mathrm{p}^{0.5}$ and neglèting tenperature, gives

$$
s<\frac{p .42 d^{1.84}}{p^{0.16}}
$$

For any givon combustion chamber $P \propto Q^{2} \propto p^{2}$ Hence eqn. (35) becomes

$$
\text { Scx } \mathrm{p}^{0.68} \mathrm{~d}^{1.84}
$$

However, from eqn. (12) $d \propto p^{-0.55}$,

$$
\text { Thus } s \propto \mathrm{p}^{-0.33}
$$

This equation shows that on any given engine featuring swirl atomisers the penetration distance of tile fuel spray is inversely proportional to the cube root of the gas pressure.

Comparing engines of different pressure ratio where the value of $P$ and hence $d m$ does not vary greatly arom one engine to another we have, from eqb. (33)

$$
5 p^{-0.16}
$$


Another effect of pressure stems from its well known influence on evaporation temperature. As the pressure is increased each individual droplet must be heated to a higher temperature before it can evaporate. This means that the "heavy ends" of the fuel, which are the last to evaporate, attain a higher temperature which accelerates the smoke producing reactions taking place within them. This effect of increase in pressure is probably quite small compared with the effects of reduced spray angle and penetration, both of which combine to increase the degree of over-richness in the smoke producing region of the flame. Thus one would expect the amount of exhaust smoke to increase with pressure and this is confirmed by experience. It is, however, of interest to speculate on what might happen in regard to smoke formation at extrenely high pressures. As the over-richness in the smoke producing region increases with pressure the situation might eventually be reached when the resulting mixiure is too xich to burn a' though evapcration continues due to the presence of hot products of combustion and to heat transfer by radiation from the flame. Under these conditions the combustion process will be similar to that in a vaporiser combustor and hence the amount of smoke produced will be quite small.

\section{HEAT IRANSFER}

High combustion pressures pose formidable problems in flametube design. These derive partly from the increase in buckling load but also from the increase in flametube wall temperature with increase in pressure. This latter effect is shown in figure 3. This figure represents the results of heat transfer calculations using the method developed by Lefebvre and herbert. ${ }^{12}$ Based on representative values of combustion chamber dimensions and velocity, it shows the influence of pressure on primary zone wall temperatures in the absence of film cooling. The increase in wall tempnrature is due partly to the increase in pressure, which increases the heat transferred from the flame to the wall, but also to the accompanying increase in inlet air temperature which impairs the capacity of the annulus air to cooi the wall by convection. In order to 
provide some indication of the relative magnitude of these two effects, figure 3 shows two lines. The full line represents the combined effects of air pressure and temperature, while the dashed line shows the results of calculations in which, above four atmospheres, the value of inlet air temperature was kept constant and the change of wall temperature could be attributed directly to the effect of pressure.

Figure 3 is useful in that it provides a quantitative assessment of the effect of pressure on flametube temperature. Unfortunately its accuracy is suspect since the calculations of flame radiation and convection at high pressure relied too heavily on measurements obtained at low pressures. They emphasize the need for more experimental data on the influence of pressure, turbulence and fuel spray characteristics on heat transfer from a flame.

The effect of increased pressure in raising wall temperature is reflected as an increase in the amount of cooling air required to provide a reasonable flametube life. This is illustrated in figure 4 which is believed to be representative of many current combustion chamber designs. This figure shows that at very high combustion pressure almost one-third of the total engine airflow is employed in film cooling the flametube.

One adverse effect of film cooling is in "chilling" the combustion reactions taking place near the chamber valls. This has an adverse effect on combustion efficiency, particularly at high altitudes where combustion is more arduous due to the relatively low reaction rates. The importance of this effeci may be judged from figure 5 which shows hich altitude combustion efficiency plotted against the percentage of air used in flare cooling for several Rolls Royce chamber designs. 13

Clearly there is a need for more data on the cooling properties of various practical types of cooling device in order to ensure that cooling air is kept to a minimum and used to maximum efficiency.

\section{IEMPERATURE TRAVERSE}

Another disadvantage to using a large amount of air in film cooling is that much of this air tends to stay near the flametube walls 
and give rise to an outlet temperature traverse that is too cold near the blade root and tip, and consequently too hot at the blade mid-height. This situation is aggravated by the circumstance that, as more air is employed in film cooling, less is available for eliminating this hot core in the temperature traverse by the normal process of dilution.

The temperature traverse is also affected by fuel spray characteristics such as droplet size, spray angle and spray penetration, since these control the pattern of combustion and hence the distribution of temperature in the hot combustion products entering the dilution zone. It has been shown that these spray characteristics are appreciably influenced by pressure, and it is to be expected therefore that temperature traverse will also vary with pressure, al though the extent of this variation will vary from one chamber to another depending on their design and, in particular, on their length. However, it is clearly highly desirable that rig work on the improvement of temperature traverse should be carried out at the maximum engine pressure.

\section{SUMMARY AND CONCLUSIONS}

(1) For any given engine an increase in combustion pressure is accompanied by
(a) a reduction in mean dropiet size
(b) a reduction in spray penetration
(c) a reduction in spray cone angle
(d) an increase in the evaporation rate number $E$, where $E$ is defined as the ratio of available evaporation time to required evaporation time. Specifically, we have Mean droplet dia., $d_{m} \propto p^{-0.55}$ Spray peitetration, $S$ \& $p^{-0.33}$

Evaporation number, $E \propto p^{1.68}$ 
(2) Since reaction rates and evaporation performance both increase with pressure it follows that any reduction in combusion efficiency with increasing pressure can be attributed to inadequate mixing.

(3) At high altitude operation the droplet lifetime may be expressed as

$$
t \propto \frac{d_{0}{ }^{2}}{p^{0.25}}
$$

but, at high combustion pressures

$$
\begin{aligned}
& t \propto \frac{d_{0}^{1.5}}{U^{0.5} 0.5} \\
& \text { where } d_{0}=\text { initial drop diameter } \\
& U=4 \text { " velocity }
\end{aligned}
$$

(4) At high pressures the evaporation performance of a combustion chamber may be expressed as

$$
\begin{aligned}
& E \propto \frac{M^{0.125}}{R^{0.072}} N^{0.375} \frac{\left(\frac{\Delta p}{q}\right)^{0.75}}{\left(\frac{\Delta P}{P}\right) 0.75} \\
& \text { where } \quad M=\text { chamber mass flow } \\
& R=\text { engine pressure ratio } \\
& N=\text { number of atomisers } \\
& \frac{\Delta P}{P}=\text { fractional chamber pressure loss }
\end{aligned}
$$

Thus at high pressures the evaporation performance is practically indepencient of pressure ratio:,

(5) It is postulated that at veiy high pressures the rapid evaporation of fuel could produce mixtures which were too rich to burn, al though evaporation could continue due to the presence of hot (but over-vitiated) products of combustion and to radiation from the flame. Under these conditions the combustion process would be similar to vaporiser combustion and the exhaust smoke would be apprecia'ly reduced. 


\section{REFERENCES}

(1) Pearson, H. Journ. Royal Aero.Soc., June 1961.

(2) Godsave, G.A.E. Fourth Symposium on Combustion, p $818,1953$.

(3) Hall, A.R. and Diederichsen, J. Fourth Symposium on Combustion p $837,1953$.

(4) Frossling, N. Beitr. Geophys. Vol.52, p170, $193 \varepsilon^{\circ}$

(5) Miesse, C.C. Jet Prop., Vol.28, No.5, 1958.

(6) De Corso, S.M. Scientifjc paper 407- G000-P3. Westinghouse Research Laboratories, July 1961.

(7) Lefebvre, A.H. and Durrant, T. Paper presented at S.A.E. National Aeronautic Meeting, Los Angeles, October 1960.

(8) Ducarme, J. Private communication

(9) Stewart, D.G. AGARD Selected Combustion Problems, p 384, 1956.

(10) Bayley, F.J. Unp'xblished work at N.G.T.E.

(11) Ingebo, R.D. N A C A.I N. 3265, 1954.

(12) Lefebvre, A.H. and Herbert, M.V. Proc. I.Mech.E., Vol.174, 1960.

(13) Halls, G.A. Unpublished work at Rolls Royce Ltd. 


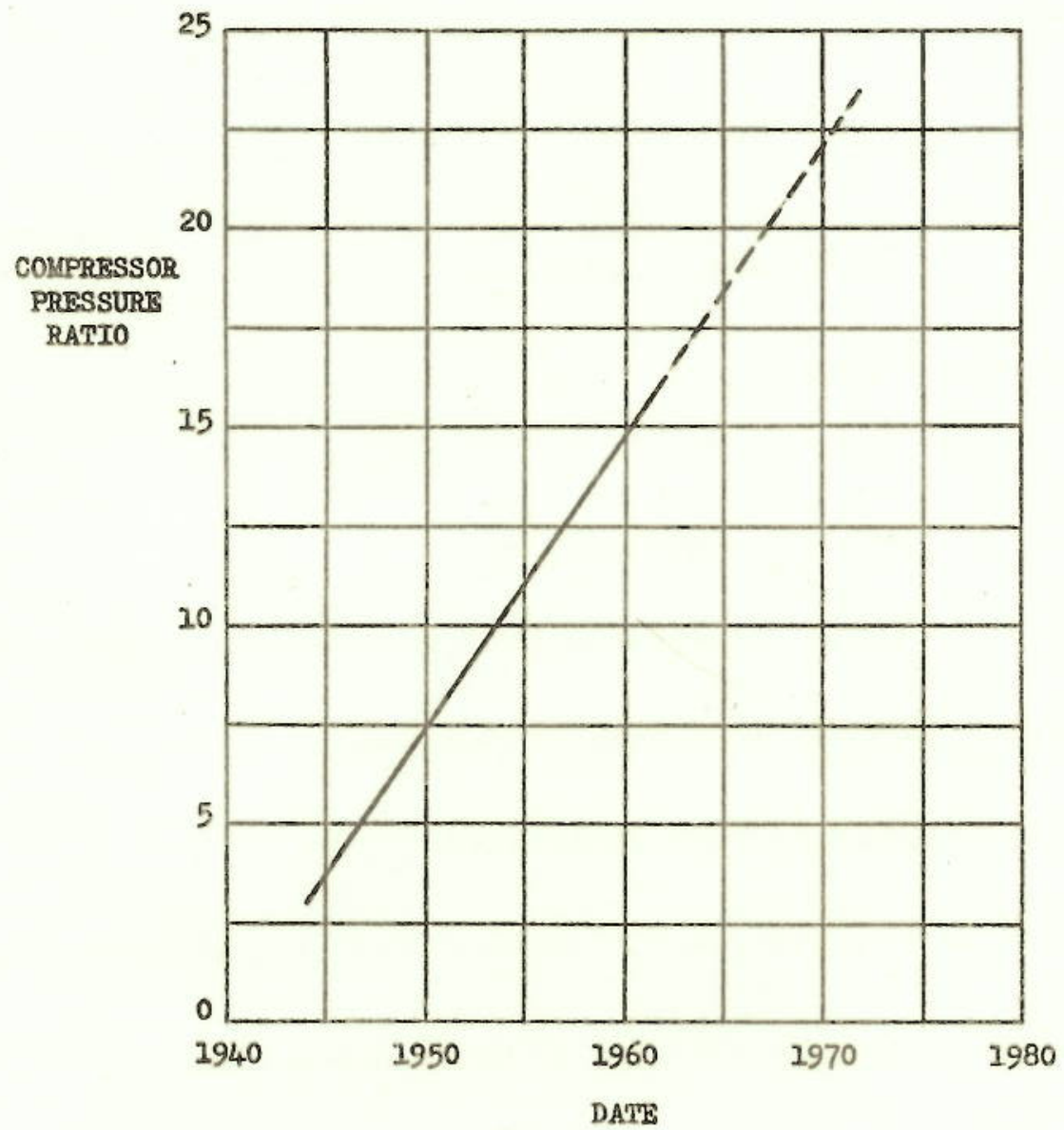

GRAPH IILUSTRATING GENERAL THEND TOWARDS

ENGTIES OF HIGHER COMPRESSION RATIO

Pigure 2 


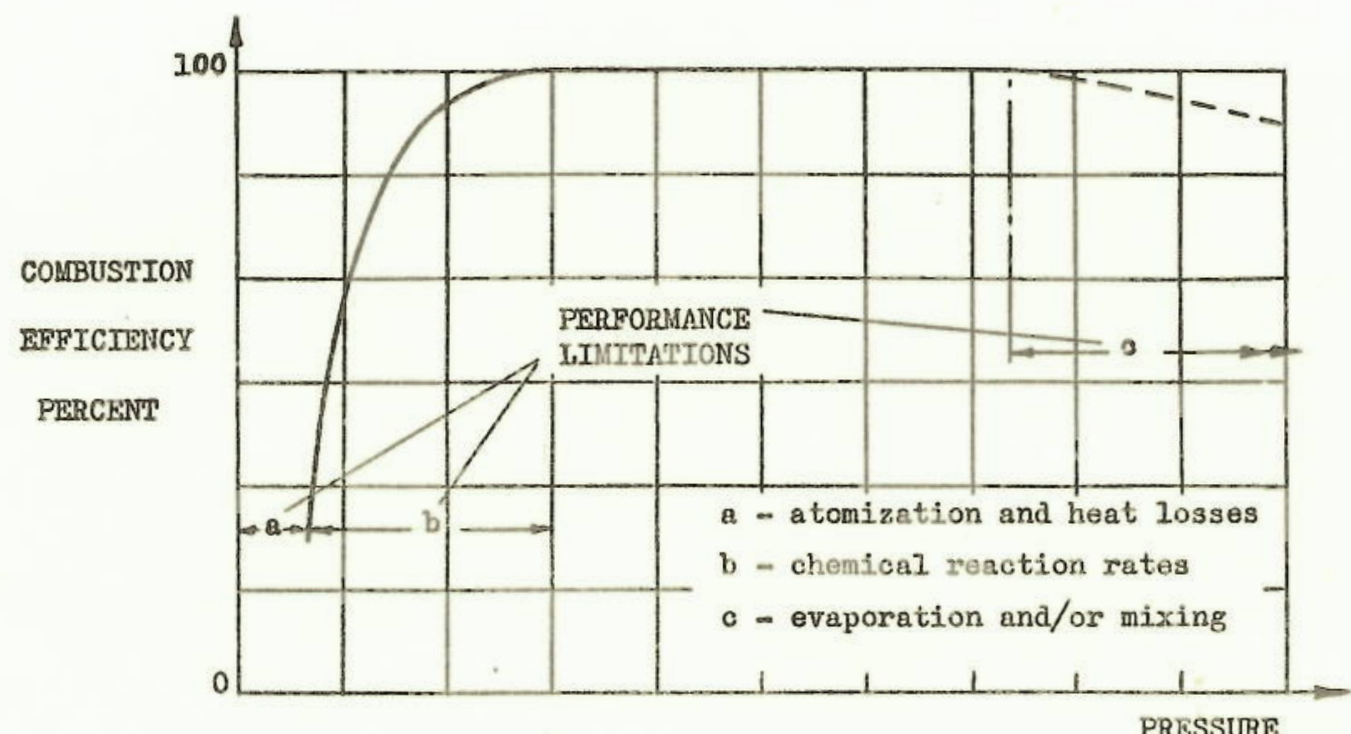

RELATIONSHIP BETWEEN COMBUS'STON EFFICTENCY

AND COMBUSTION PRESSURE

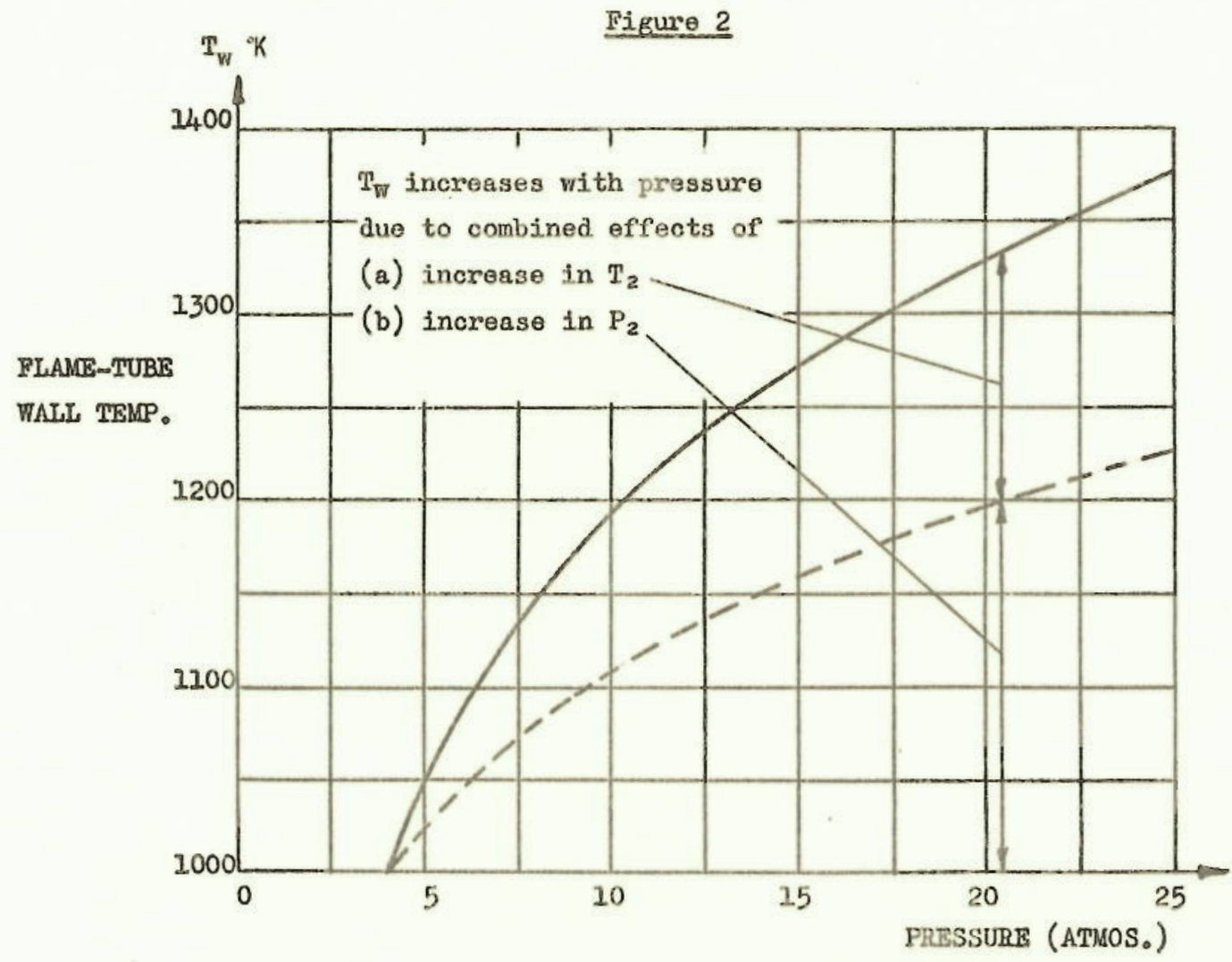

EFFECT OF INCREASING COMBUSTION PRFSSURE

ON FIAME-TUBE WALL TEMPERATURE 


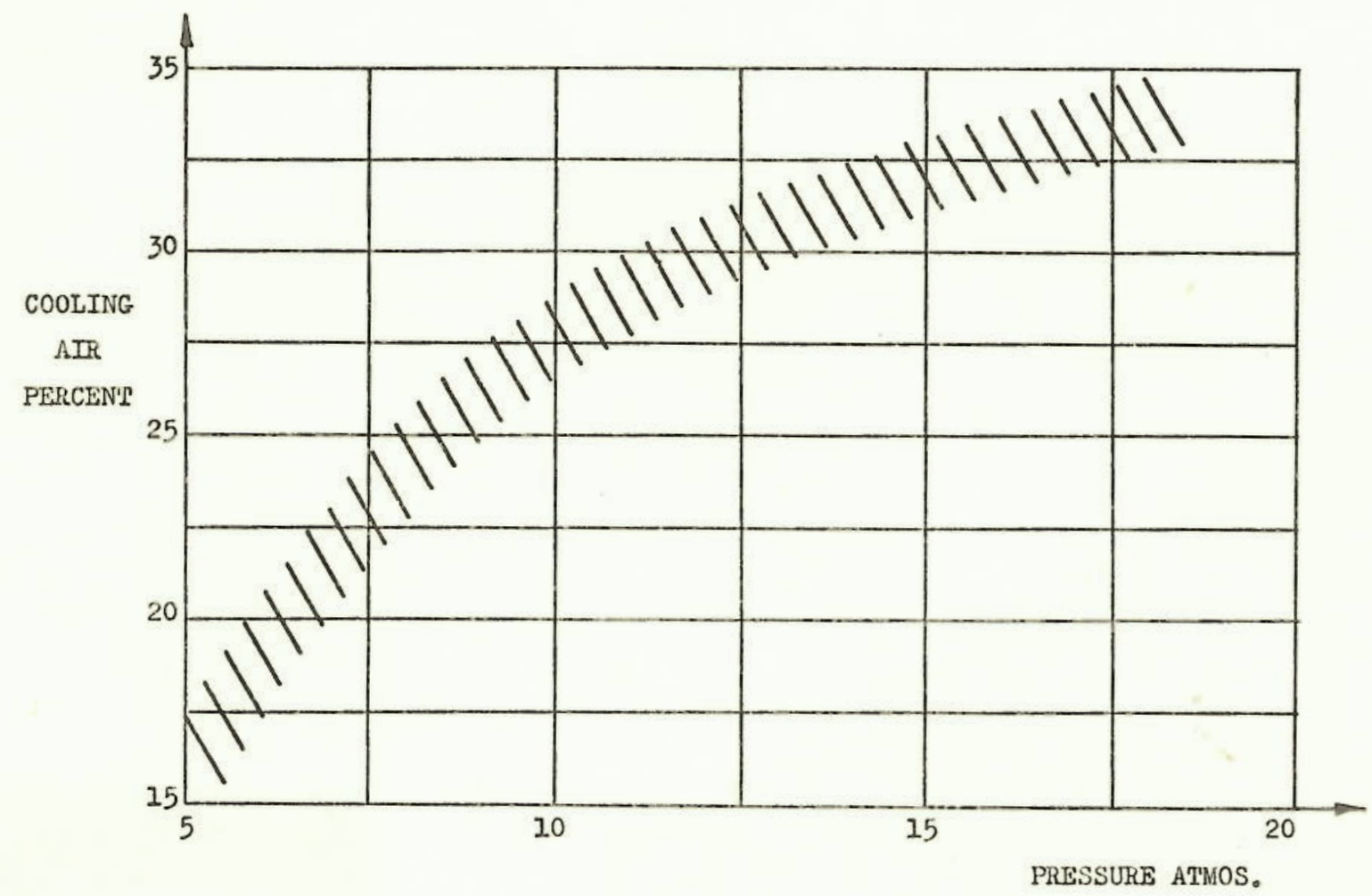

PERCENTAGE OF TOPAL CHAMBER $\Lambda$ IR

GMPLOYED IN FLAMT-TUBE FILM COOLING

Figure 4

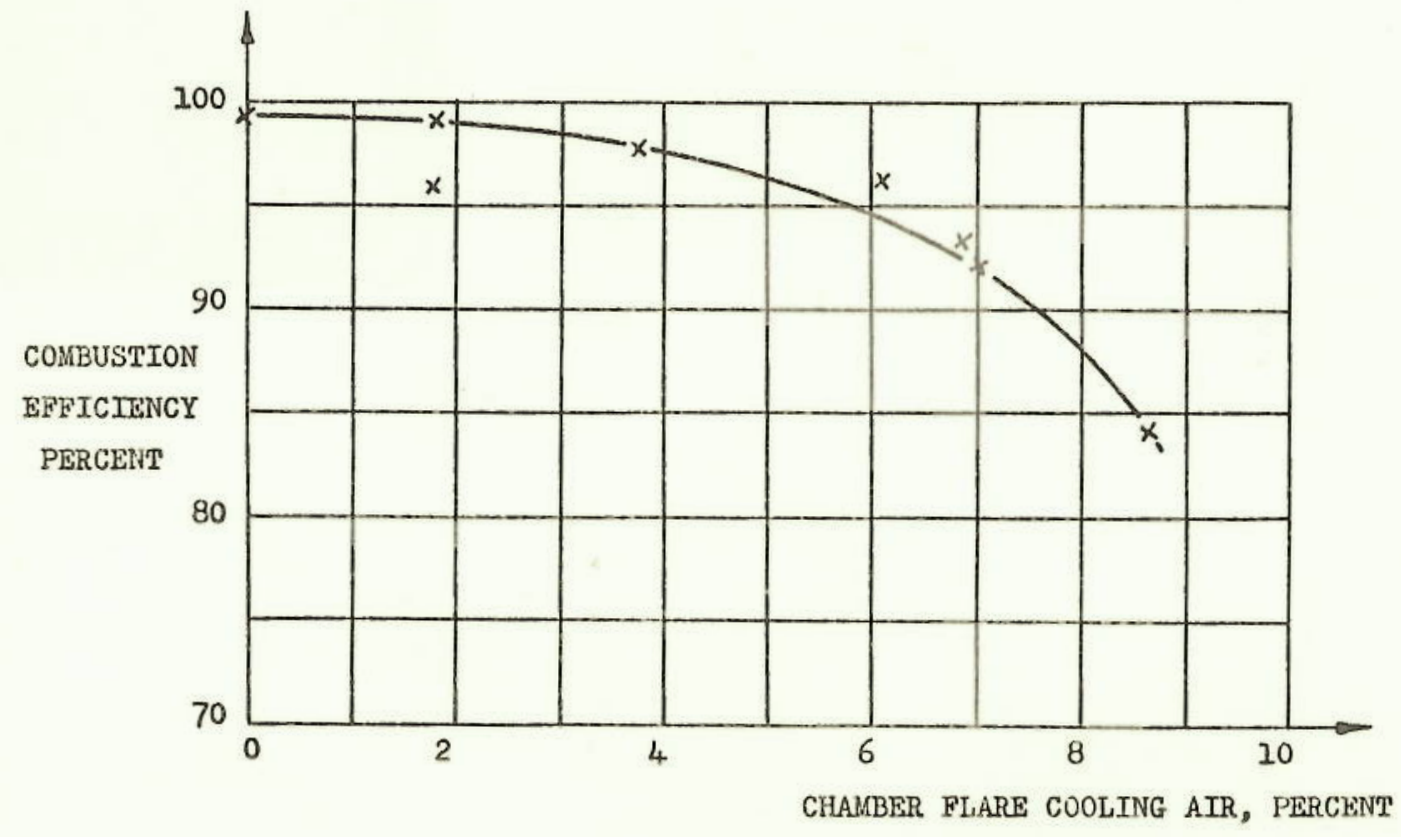

EFFECT OF FLARE COOLING ATR QUANTITY ON

HIGH ALTITUIE COMBUSTION EFFICIENCY

Pigure 5 